\title{
CD56 Expressing Cell Measurement
}

National Cancer Institute

\section{Source}

National Cancer Institute. CD56 Expressing Cell Measurement. NCI Thesaurus. Code C103370.

A count of the CD56 expressing cells per unit of a biological specimen. 